\title{
JURISPRUDENCIA AMBIENTAL EN LA COMUNIDAD DE MADRID (SEGUNDO SEMESTRE 2018)
}

\author{
ANTONIO FORTES MARTÍN \\ Profesor titular de Derecho Administrativo \\ Universidad Carlos III de Madrid
}


Sumario: 1. Licencia de funcionamiento, poderes de "policía ambiental" y modificación de las condiciones de la actividad. 2. Principio de desarrollo territorial y urbano sostenible.

\section{LICENCIA DE FUNCIONAMIENTO, PODERES DE "POLICÍA} AMBIENTAL" $Y$ MODIFICACIÓN DE LAS CONDICIONES DE LA ACTIVIDAD.

La Sentencia del Tribunal Superior de Justicia de Madrid (en adelante TSJM) número 51/2018, de 5 de febrero de 2018 nos sitúa ante una temática "vieja" pero de actual vigencia.

El origen de la controversia es un Acuerdo municipal por el que se decide el precinto de unos emisores acústicos de una central telefónica. $Y$ el interés del pronunciamiento que traemos a esta crónica radica en la importancia de las licencias de funcionamiento como autorizaciones operativas que permiten (incluso el TSJM precisa del "deber de la Administración") de modificar el contenido de la autorización inicialmente otorgada "para mantenerlo correctamente adaptado, a lo largo de su vigencia, a las exigencias del interés público".

Pese a su derogación formal, la vigencia del viejo Reglamento de actividades molestas, insalubres, nocivas y peligrosas en la Comunidad de Madrid cobra especial fuerza respecto de la eventual actuación de los ayuntamientos con poderes de "policía ambiental". Una actuación que no finaliza con la concesión y, en su caso, revocación de las licencias de apertura. Tal y como reconoce la jurisprudencia del Tribunal Supremo de la que se hace eco el pronunciamiento objeto de esta crónica, las Corporaciones municipales "disponen de unos poderes de intervención de oficio y de manera constante con la finalidad de salvaguardar la protección de personas y bienes pudiendo imponer, en consecuencia, cualesquiera correcciones y adaptaciones que estimen necesarias sin que ello suponga una ilícita vuelta contra los propios actos".

A mayor abundamiento, el citado Reglamento de actividades molestas, insalubres, nocivas y peligrosas es el que recreaba esa posibilidad de intervención administrativa de corte ambiental en una fase secuencial que se inicia con el procedimiento que da pie a la obtención de la licencia de instalación. Continúa, después, con la visita previa de comprobación técnica para posibilitar el ejercicio de la actividad autorizada mediante el otorgamiento, 
en su caso, de la licencia de apertura. $Y$ es en el tercer estadio donde se concentra todo el interés como quiera que "iniciado el curso de la actividad no por ello queda despojada la Administración de posibilidades de actuación respecto de aquélla, pues las licencias reguladas en este Reglamento constituyen un supuesto típico de autorización de funcionamiento, en cuanto que autorizan el desarrollo de una actividad a lo largo del tiempo y genera una relacion permanente con la Administración, que en todo momento podrá acordar lo preciso para que la actividad se ajuste a las exigencias de interés público -condición siempre implícita en este tipo de licencias-“.

Justamente a este resultado conducen los artículos 35 a 38 del Reglamento de actividades molestas, insalubres, nocivas y peligrosas como base jurídica cabalmente formalizada que posibilita, en el caso que nos ocupa, que si una actividad funciona con deficiencias técnicas, un ayuntamiento pueda requerir al titular la subsanación de las mismas. Y si el incumplimiento persiste proceder a acordar la clausura de la actividad como en el concreto supuesto resuelto por el TSJM lo fue confirmar la legalidad del acuerdo de precinto de los emisores acústicos del sistema de climatización de una central telefónica por exceder el nivel de ruido conforme a la normativa vigente. Ello sin prejuzgar que una vez realizadas las medidas correctoras oportunas y quedando demostrado el funcionamiento correcto sin superarse el nivel de emisión admitido el ayuntamiento pueda acordar el levantamiento del precinto.

\section{PRINCIPIO DE DESARROLLO TERRITORIAL Y URBANO SOSTENIBLE.}

En este segundo apartado de la crónica ambiental de jurisprudencia nos ocupamos de la Sentencia del Tribunal Constitucional (TC) núm 75/2018, de 5 de julio.

La razón que explica el interés de este pronunciamiento se explica por lo siguiente. En primer lugar, porque la Sentencia resuelve un recurso de inconstitucionalidad interpuesto por el Consejo de Gobierno de la Comunidad de Madrid. $Y$, en segundo término, porque en lo que aquí más interesa, el recurso de inconstitucionalidad se dirige contra una serie de preceptos de la Ley 8/2013, de 26 de junio, de rehabilitación, regeneración y renovación urbanas que modificaban, a su vez, determinados preceptos del RD-Legislativo 
2/2008, de 20 de junio por el que se aprueba el Texto Refundido de la Ley de suelo. Concretamente, el Gobierno de la Comunidad de Madrid argumenta que los preceptos impugnados no tienen cobertura en los títulos competenciales estatales vulnerando por ello las competencias autonómicas en materia de urbanismo y vivienda, procedimiento administrativo, fomento del desarrollo económico, y desarrollo legislativo en materia de protección del medio ambiente. Cabe apuntar, además, como resulta sabido, que la aprobación ulterior del RD-Legislativo 7/2015, de 30 de octubre, por el que se aprueba el actualmente vigente Texto Refundido de la Ley de suelo y rehabilitación urbana provocó la derogación de todos los preceptos objeto de impugnación. Si bien el contenido de esos preceptos de la Ley 8/2013 pasaron a incorporarse al texto del RD-Legislativo 7/2015. Es por esta razón por la que el recurso contra los preceptos inicialmente impugnados de la Ley 8/2013 no pierde su objeto por encontrar justa correspondencia en los preceptos equivalentes del Texto Refundido actual.

En buena lógica, el objeto del recurso y la posterior decisión del TC excede el alcance mucho más limitado de esta crónica centrando nuestra atención únicamente la impugnación estrictamente ambiental por lo que se refiere, en concreto, al artículo 2 del RD-Legislativo 2/2008, de 20 de junio referido al principio de desarrollo territorial y urbano sostenible en la redacción dada por la Disposición final $12^{a}$ apartado primero, de la Ley 8/2013.

Dentro de la impugnación del artículo 2 hay que distinguir por un lado los apartado primero y cuarto. A juicio del Gobierno de la Comunidad de Madrid su configuración normativa condiciona las políticas públicas y el modelo urbanístico de competencia autonómica. Y el TC decide la desestimación del recurso porque los preceptos impugnados encuentran cobertura constitucional en el artículo 149.1 CE apartados 1.13 y 23. Cabe tener presente además que la desestimación descansa en el pronunciamiento previo del propio TC mediante Sentencia 141/2024 (F.J 6 B), de 11 de septiembre por la que se resolvió el recurso de inconstitucionalidad interpuesto entre otros, por el Consejo de Gobierno de la Comunidad de Madrid, contra la Ley 8/2007, de 28 de mayo de suelo y contra el RD-Legislativo 2/2008, de 20 de junio, por el que 
se aprueba el Texto Refundido de la Ley de suelo.

De otra parte, los apartados segundo y tercero del artículo 2 del RD-Legislativo 2/2008, de 20 de junio en la redacción dada por la Disposición final $12^{a}$ de la Ley 8/2013. Estos apartados corren la misma suerte que los anteriores y el TC aprecia que no hay vulneración de la competencia autonómica. Es más, el TC acoge la tesis del Abogado del Estado conforme a la cual los términos de todo punto generales empleados por el legislador estatal no fijan un contenido concreto del principio de desarrollo sostenible ni tampoco imponen un modelo acabado del mismo. A mayor abundamiento, el Alto Tribunal detalla que el apartado segundo del artículo 2 contempla un conjunto de prescripciones que se derivan directamente del principio de desarrollo sostenible, bien en forma de principio general, bien mediante directrices de actuación de los poderes públicos. Pero en ambos casos con pleno respeto al orden constitucional de distribución de competencias conforme ya se expuso en la Sentencia del TC $141 / 2014$.

Por lo que se refiere al apartado tercero, abundando sobre el apartado inmediatamente anterior, se introduce un mandato específico para los poderes públicos en relación con el medio urbano a la hora de posibilitar la consecución de fines como la movilidad sostenible, la accesibilidad universal, el uso eficiente de la energía y las energía renovables y la prevención y minimización del impacto negativo de los residuos urbanos y la contaminación. $Y$ la incidencia de la Disposición final $12^{\text {a }}$ de la Ley 8/2013 en el artículo 2 resulta en una ampliación en el contenido de las directrices de actuación dirigidas a orientar a los poderes públicos, "si bien no se aprecia una alteración sustancial del fin último y común ya presente en la redacción original del precepto; esto es, concretar el principio de desarrollo sostenible". Una concreción que, a juicio del TC, "encuentra amparo en los números 13 y 23 del artículo 149.1 CE". Porque el Estado, no pudiendo imponer, sí puede incidir o encauzar el modelo territorial o urbanístico, que las Comunidades Autónomas finalmente consideren más pertinente, mediante directrices y normas básicas que aquéllas han de respetar. 
En definitiva, se desestima la impugnación dirigida contra el artículo 2 porque en ningún momento se impide a las Comunidades Autónomas optar por el modelo concreto de ordenación territorial y urbanística que estimen oportuno dado que "los preceptos cuestionados cumplen una función básica en la construcción del sistema jurídico de ordenación del territorio y utilización del suelo, debiendo calificarse como plenamente conformes al orden constitucional de distribución de competencias". 